\title{
Diastematomyelia in Kurdistan region of Iraq: A case series analysis of 27 cases reported in Erbil
}

\section{Abstract}

Background and objective: Globally, diastematomyelia accounts for $5 \%$ of all congenital spinal cord defects. Clinically, symptoms of diastematomyelia are non-specific, can be progressive, and can become symptomatic at any age. This study was carried out to describe neurological, radiological and surgical findings of diastematomyelia cases reported in Erbil city of Iraq.
\end{abstract}

Methods: A retrospective review of diastematomyelia was carried out in three neurosurgical centers in Erbil city of Kurdistan region of Iraq between $1^{\text {st }}$ January 2003 and $1^{\text {st }}$ January 2013. Diagnosis of this anomaly was based on CT and MRI with surgical dissection in one case. In patients with contraindication for MRI and CT scan, the diagnosis was based on lumbar myelography. Surgical interventions included surgical decompression and laminectomy with timely follow-up at every six months to assess the outcomes after the surgical intervention.

Results: A total of 27 cases were included in this study with a mean age of 13 years (ranging from 1-19 years) and a female to male ratio of 2.9:1. Spinal deformities (66.7\%) were the main complaints for patients to seek medical advice. Clinically, $89 \%$ of the patients had a huge spinal disfigurement, and $74 \%$ had a mid-line thoracic or lumbar cutaneous variation from the norm. Neurologically, $59 \%$ of the patients had a least neurological disability. Radiologically, $96 \%$ showed inter-pedicular separation and spina bifida, $59 \%$ scoliosis, and $55.6 \%$ boney spicule. Intra-operatively, around $63 \%$ of the cases had boney septum separating the dissected hemi-cords; $70 \%$ of the septa located in the lumbar region. Post-operatively, none of the patients experienced decay in their neurologic status after surgery. Over the long term, two patients were slightly improved, and another two had an increased neurological deficit, one patient had better reflexes, but increasing deformity of the foot and 14 patients were unchanged. None of the patients had contamination, pseudoarthrosis, or loss of remedy amid the subsequent visit.

Conclusion: Despite the slight postoperative improvement, all patients with the established preoperative deficit still had residual neurological postoperative deficits and only a low proportion of them slightly improved.

Keywords: Diastematomyelia; Neurological findings; Spinal deformities.

\section{Introduction}

Diastematomyelia, also known as split cord malformation (SCM), is a rare congenital abnormality affecting the spinal canal due to abnormal notochord development and abnormal cleft of the spinal canal during the inherent stage where the upper lumbar piece of the spinal string parts. This abnormality is characterized by sagittal or longitudinal splitting of the spinal canal and cord with or without bony or fibrous septum. ${ }^{1}$ The split cord (hemi-cord) will rejoin in the lower piece of the septa. This may occur anywhere in the spine, but most commonly between T9 and S1 (rarely within the cervical region). It is a subtype of closed spinal dysraphism. ${ }^{2}$ Two types of this abnormality are described depending on the presence or absence of bony spur and number of the dural sac surrounding 
the split cord. $^{3-5}$ Type । deformity (symptomatic type) characterized by the presence of bony septum that produces two separate dural sacs for each hemi-cord, while type II deformity (nonsymptomatic type) characterized by the absence of bony septum leaving one dural sac to surround the hemi-cords. ${ }^{4-6}$ Globally, diastematomyelia accounts for $5 \%$ of all congenital spinal cord defects. Clinically, symptoms of diastematomyelia are nonspecific, can be progressive, and can become symptomatic at any age. ${ }^{7}$ Around $60-70 \%$ of patients with diastematomyelia have inherent scoliosis. ${ }^{8}$ Although this defect is diagnosed at childhood, with recent advances in imaging technologies, diagnosis become frequent in adult age. ${ }^{7}$ Nationally, scarce information is available in Kurdistan region of Iraq on this congenital defect. Therefore, this study was carried out to describe neurological, radiological and surgical findings of diastematomyelia cases reported in Erbil city of Kurdistan region.

\section{Methods}

We carried out a retrospective review of diastematomyelia reported in three neurosurgical centers of Erbil teaching hospital, Hawler private hospital and Par private hospital in Erbil city of Kurdistan region between $1^{\text {st }}$ January 2003 and $1^{\text {st }}$ January 2013. All patients diagnosed as having diastematomyelia in these three centers during the study period were included in this study. Diagnosis of this anomaly was based on magnetic resonance imaging (MRI) and computerized tomography (CT) scan, with surgical dissection in one case. In patients with contraindications for MRI and CT scan, the diagnosis was based on lumbar myelography. Clinical and neurological examinations were conducted for all patients. Surgical interventions including surgical decompression and laminectomy were performed with timely follow-up at every six months to assess the outcomes (changes) after the surgical intervention. The protocol of the study was approved by the research ethics committee of the college of medicine of Hawler medical university. Informed consent was obtained from all patients or their guardian before being enrolled in the study. Descriptive statistical analysis was performed, and the results of categorical variables were presented in the form of frequencies and percentages. Results of numerical variables were presented in the form of means and standard deviations.

\section{Results}

A total of 27 cases were included in this study, their mean age $( \pm$ SD) was $13 \pm 5.6$ years, ranging from 1- 19 years; 23 of them were below ten years of age. Twenty cases (74\%) were females with a female: male ratio of 2.9: 1 . Spinal deformities (66.7\%) were the main complaint in patients seeking medical advice (Table 1 ).

Table 1: Main deformities of diastematomyelia demonstrated in patients seeking medical advice.

\begin{tabular}{lcc}
\hline Associated deformities & No. & (\%) \\
\hline Spinal deformity & 18 & $(66.7)$ \\
Gait deformity & 3 & $(11.1)$ \\
Foot deformity & 4 & $(14.8)$ \\
Untreated myelomeningocele & 2 & $(7.4)$ \\
Total & 27 & $(100.0)$ \\
\hline
\end{tabular}


Pre-operatively, clinically 24 (88.9\%) of the patients had a huge spinal disfigurement, $20(74.1 \%)$ had a mid-line thoracic or lumbar cutaneous variation from the norm, and 12 (44.4\%) had remarkable foot disfigurements. Neurologically, 16 (59.3 \%) of the patients had a least neurological disability. Radiologically, $96.3 \%$ showed inter-pedicular separation and spina bifida, $59.3 \%$ scoliosis, and $55.6 \%$ boney spicule. Details are shown in Table 2.

Table 2: Pre-operative findings of the 27 patients with diastematomyelia included in the study.

\begin{tabular}{|c|c|c|c|}
\hline Variables & $\mathbf{N}$ & No. & $(\%)$ \\
\hline \multicolumn{4}{|l|}{ Clinical findings } \\
\hline Huge spinal disfigurement & 27 & 24 & $(88.9)$ \\
\hline Thoracic/ lumbar cutaneous variation & 27 & 20 & $(74.1)$ \\
\hline Hair patch & 20 & 11 & $(55.0)$ \\
\hline Lipoma & 20 & 4 & $(20.0)$ \\
\hline Nevus & 20 & 2 & $(10.0)$ \\
\hline Sacral dimple & 20 & 2 & $(10.0)$ \\
\hline Hemangioma & 20 & 1 & $(5.0)$ \\
\hline Foot disfigurement & 27 & 12 & $(44.4)$ \\
\hline Neurological findings & 27 & & \\
\hline Least neurological disability & 27 & 16 & $(59.3)$ \\
\hline Paraplegia and myelomeningocele & 27 & 2 & $(7.4)$ \\
\hline Spastic paraparesis & 27 & 1 & (3.7) \\
\hline \multicolumn{4}{|l|}{ Radiological findings } \\
\hline Bony spicule & 27 & 15 & $(55.6)$ \\
\hline Inter-pedicular separation with spina bifida & 27 & 26 & $(96.3)$ \\
\hline Scoliosis & 27 & 16 & $(59.3)$ \\
\hline Disappointments of arrangement & 16 & 7 & $(43.8)$ \\
\hline Disappointment of division & 16 & 3 & $(18.8)$ \\
\hline Blended deformities & 16 & 6 & $(37.5)$ \\
\hline
\end{tabular}


Intra-operatively, around $63 \%$ of the cases had boney septum separating the dissected hemi-cords, and $70 \%$ of the septa located in the lumbar region (Table 3). Post-operatively, only 19 patients were adequately followed-up for a minimum of six months after laminectomy. Based on preoperative and postoperative neurological examination and, in a few cases, on electromyography and muscle testing, none of the patients experienced decay in their neurologic status after surgery. Over the long term, two (10.5\%) patients were slightly improved, two $(10.5 \%)$ patients had an increased neurological deficit, and one (5.3\%) patient had better reflexes but increasing deformity of the foot. The remaining 14 $(73.7 \%)$ patients were unchanged. One patient died of cardiac arrest during laminectomy. In one patient who had related myelomeningocele, postoperative cerebrospinal liquid spillage was reported. None of the patients had contamination, pseudarthrosis, or loss of remedy amid the subsequent visit.

Table 3: Intra-operative findings in all patients.

\begin{tabular}{llll}
\hline Variable & $\mathbf{N}$ & No. & $\mathbf{( \% )}$ \\
\hline Type of the septum & 27 & 17 & $(62.96)$ \\
Bony septum (type I) & 27 & 10 & $(37.04)$ \\
Cartilaginous septum (type II) & & & \\
Site of the septum & 27 & 8 & $(29.6)$ \\
Thoracic & 8 & 1 & $(12.5)$ \\
$3^{\text {rd }}$ thoracic & 8 & 1 & $(12.5)$ \\
$5^{\text {th }}$ thoracic & 8 & 2 & $(25.0)$ \\
$7^{\text {th }}$ thoracic & 8 & 1 & $(12.5)$ \\
$8^{\text {th }}$ thoracic & 8 & 1 & $(12.5)$ \\
$9^{\text {th }}$ thoracic & 8 & 2 & $(25.0)$ \\
$10^{\text {th }}$ thoracic & 27 & 19 & $(70.4)$ \\
Lumbar $^{\text {st }}$ & 19 & 6 & $(31.6)$ \\
$2^{\text {nd }}$ lumbar & 19 & 5 & $(26.3)$ \\
$3^{\text {rd }}$ lumbar & 19 & 6 & $(31.6)$ \\
$4^{\text {th }}$ lumbar & 19 & \\
\hline
\end{tabular}




\section{Discussion}

In the current study, the mean age of the affected patients was 13 years. This is much higher than that in northern India (5.7 years), ${ }^{9}$ in Paris of France (2.3 years) ${ }^{10}$ and Egypt (5.5 years). ${ }^{11}$ However, it is lower than that reported by another study (37.8 years). ${ }^{12}$ Females were predominantly affected in the current study with a female: male ratio of 2.9:1. This female predominance was similarly reported with different ratios in studies in Paris, ${ }^{10}$ Egypt, ${ }^{11}$ Los Angeles of United States, ${ }^{13}$ and China. ${ }^{14}$ However, the study in Northern India ${ }^{9}$ reported a predominance of males with a male to female ratio of 1.5:1. Spinal deformities were the main deformity associated with diastematomyelia constituting $66.7 \%$ of deformities in this study. This finding is similar to that reported in Boston in the United States, ${ }^{15}$ but it is higher than that reported in New Delhi of India, ${ }^{16}$ and Egypt. ${ }^{11}$ Around $74 \%$ of patients had thoracic or lumbar cutaneous variations. This is slightly higher than that reported in the Boston, ${ }^{15}$ and Paris studies, ${ }^{10}$ but it is lower than that reported in Los Angles study. ${ }^{13}$ Hair patches were the main cutaneous lesions; a finding, which is similarly reported in Boston, ${ }^{15}$ and Egypt studies, ${ }^{11}$ while in Los Angeles study congenital dermal sinus was the main lesion, ${ }^{13}$ and in Paris study, the port-wine stain was the main lesion. ${ }^{10}$ At the operation, nearly $63 \%$ of cases of diastematomyelia had boney septum; a finding which is slightly lower than that reported in Egypt study. ${ }^{11}$ These lesions were located mainly at the lumbar region which is similarly reported in Boston, ${ }^{15}$ and India studies. ${ }^{17}$ However, in the other Indian study in New Delhi, ${ }^{16}$ the lesions were located mainly in the thoracic region. Postoperatively, Mahapatra ${ }^{17}$ reported that $50 \%$ of their patients improved, $44 \%$ remain unchanged, and $6 \%$ suffered from immediate postoperative deterioration. On the other hand, Borkar et al. ${ }^{16}$ reported that $71.7 \%$ of patients were improved, $13.2 \%$ unchanged, and $15.1 \%$ suffered postoperative deterioration. In this study, however, only $10.5 \%$ of patients were slightly improved, $10.5 \%$ had increased neurological deficit, $5.3 \%$ had better reflexes but with increased foot deformity, and $73.7 \%$ remained unchanged. Postoperative cerebrospinal fluid spillage was reported in one patient (3.7\%), and none of the patients had wound contamination, while Kumar et al. ${ }^{9}$ reported CSF leakage in $33 \%$, wound contamination in 14\%, and meningitis in $8 \%$ of patients, and Gan et al. ${ }^{18}$ reported postoperative wound infection in $11.1 \%$ of patients.

\section{Conclusion}

Despite the slight postoperative improvement, all patients with the established preoperative deficit still had residual neurological postoperative deficits and only a low proportion of them slightly improved.

\section{Competing interests}

The authors declare that they have no competing interests.

\section{References}

1. Moradi E, Hanaei S, Shahjouei S, Habibi Z, Nejat F. Trifid cord; very rare presentation of split cord malformation. J Spine 2016; 5:311.

2. Upasani VV, Ketwaroo PD, Estroff JA, Warf BC, Emans JB, Glotzbecker MP. Prenatal diagnosis and assessment of congenital spinal anomalies: Review for prenatal counseling. World J Orthop 2016; 7(7):406-17.

3. Sonigo-Cohen $P$, Schmit $P$, Zerah $M$, Chat $L$, Simon I, Aubry MC, et al. Prenatal diagnosis of diastematomyelia. Childs Nerv Syst 2003; 19(78):555-60.

4. Olaide A, Venkatraman S, Farbod A. Type I split cord malformation: Literature review, case presentation and surgical technique. JSM Neurosurg Spine 2014; 2(3):1026.

5. Sack AM, Khan TW. Diastematomyelia: Split cord malformation. Anesthesiology 2016; 125 (2):397.

6. Garg K, Mahapatra AK, Tandon V. A rare case of type $1 \mathrm{C}$ split cord malformation with single dural sheath. Asian J Neurosurg 2015; 10(3):226-8.

7. McShane A, Temponi EF, Millar A. Diastematomyelia- an unusual presentation to rheumatology. Rheumatology (Sunnyvale) 2016; 6(3):204. 
8. Bekki H, Morishita Y, Kawano O, Shiba K, Iwamoto Y. Diastematomyelia: A surgical case with long-term follow-up. Asian Spine J 2015; 9(1):99-102.

9. Kumar R, Singh S. Spinal dysraphism: trends in northern India. J Neurosurg Pediatr 2003; 38(3):133-45.

10. Guggisberg D, Hadj-Rabia S, Viney C, Bodemer C, Brunelle F, Zerah M, et al. Skin markers of occult spinal dysraphism in children: a review of 54 cases. Arch Dermatol 2004; 140(9):1109-15.

11. Kamal HM. Management of type I split cord malformation: Surgical technique and clinical outcome. Med J Cairo Univ 2010; 78(1):247-52.

12. Russell NA, Benoit BG, Joaquin AJ. Diastematomyelia in adults. Pediatr Neurosurg 1990-91; 16(4-5):252-7.

13. Anderson FM. Occult spinal dysraphism: a series of 73 cases. Pediatrics 1975; 55(6):826-35.

14. Cheng B, Li FT, Lin L. Diastematomyelia: A retrospective review of 138 patients. J Bone Joint Surg Br 2012; 94(3):365-72.

15. Hood RW, Riseborough E, Nehme A, Micheli L, Strand R, Neuhauser E. Diastematomyelia and structural spinal deformities. J Bone Joint Surg Am 1980; 62(4):520-8.

16. Borkar SA, Mahapatra A. Split cord malformations: A two years experience at AlIMS. Asian J Neurosurg 2012; 7(2):56-60.

17. Mahapatra A. Split cord malformation: A study of 300 cases at AlIMS 1990-2006. J Pediatr Neurosci 2011; 6(3):41-5.

18. Gan YC, Sgouros S, Walsh AR, Hockley AD. Diastematomyelia in children: treatment outcome and natural history of associated syringomyelia. Child's Nerv Syst 2007; 23(5):515-9. 